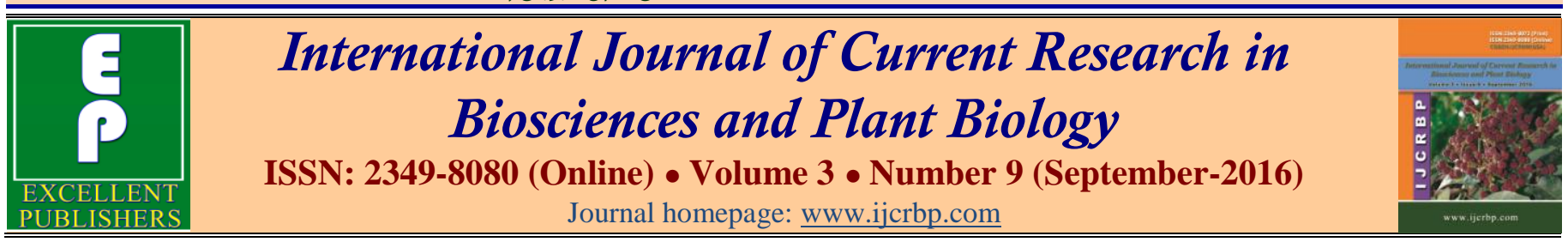

Review Article

doi: http://dx.doi.org/10.20546/ijcrbp.2016.309.008

\title{
A Review on In Vitro Culture Studies of a Traditional Medicinal Herb- Achyranthes aspera L.
}

\author{
Karuppiah Nandhini ${ }^{1}$ and Sethuraman Ramakrishnan ${ }^{2 *}$ \\ ${ }^{1}$ Department of Plant Science, Manonmaniam Sundaranar University, Tirunelveli- 627 012, Tamil Nadu, India \\ 'Department of Botany, Tagore Arts College, Puducherry- 605 0o8, India \\ *Corresponding author.
}

\begin{abstract}
A b s tract
The traditional medical practitioners use many common plants and weeds to treat number of diseases. One such medicinal plant is Achyranthes aspera L. It possesses variety of uses in healing human diseases including asthma, cough; and acts as antiphlegmatic, antiperiodic, diuretic, purgative, laxative, oedema, dropsy, piles, boils, eruptions of skin, snake bites and moreover used as tooth brush. Secondary metabolites of medical importance have been isolated from this plant grown in vivo. At this juncture it is worth to discuss in vitro culture studies of this valuable plant. This would help the scientists to micropropagate and protect this plant species in addition to providing an opportunity to extract active metabolites. The present review is aimed at the documentation of developments made in cloning of A. aspera.
\end{abstract}

\author{
Article Info \\ Accepted: 19 August 2016

\section{Ke ywords} \\ Achyranthes aspera $\mathrm{L}$. \\ Callus \\ In vitro cultures \\ Multiple shoots \\ Traditional medicine
}

Available Online: 06 September 2016

\section{Introduction}

The traditional medicinal plant Achyranthes aspera L. is commonly known as 'prickly-chaff flower' which belongs to the family Amaranthaceae. In Tamil it is called as "Nayuruvi". It is an erect perennial herb occurs on the roadsides, field boundaries and waste places as a weed throughout India, Baluchistan, Ceylon, Tropical Asia, Africa, Australia and America. It occurs up to an altitude of $2100 \mathrm{~m}$ (Verma, 2014).

Report made by World Health Organization (WHO, 1993 ) indicates that more than $80 \%$ of the world's population depends on traditional herbal medicines for their primary health care. The A. aspera has various medicinal properties. Traditional medical practitioners use this plant for many health problems like asthma, cough, antiphlegmatic, antiperiodic, diuretic, purgative, laxative, edema, dropsy, piles, boils and eruptions of skin etc (Srivastav et al., 2011). In addition, the paste made of either flowers or seeds used for poisonous snakes and reptile bites, and also used in night blindness and cutaneous diseases (Nadkarni, 2009). To improve appetite and cure various types of gastric disorders the fume of A. aspera mixed with Smilax ovalifolia roots is inhaled (Bhattaraj, 1992). Fresh root is used as tooth brush to relieve pain and clean teeth (Ganesan et al., 2006).

In recent times, over utilization of plants pose a greater threat to the natural resources (Pande et al., 2007). Tissue culture experiments have come in handy to overcome this critical situation and conserve several plant species found on the earth. This review article is written with the intention of providing up to date developments made in tissue culture studies of $A$. aspera. Research studies have been made to clone this plant in vitro by various scientific groups. They are documented here to help the scholars to propagate, and isolate active compounds from it which in turn would provide the pavement for the 
formulation of drugs against multiple human diseases.

\section{Tissue culture experiments of $A$. aspera}

In vitro culture experiments simultaneously employ chemically defined specific media augmented with plant growth regulators (PGRs) and opt protocol for eliminating the contaminants from the explants. Type of surface sterilization agents and growth promoting chemicals together are responsible for successful cloning/ propagation of any plant species. Because, explants collected from the field grown plants are inhabited by many microorganisms. We begin our discussion with the surface sterilization protocols adapted for various explants of $A$. aspera studies and discuss cloning methods employed for propagation.

\section{Surface sterilization of explants}

Success on culture of plant tissues on chemically defined media relies upon avoidance or prevention of the growth of contaminating microbes. Very often microbial contamination of plant tissue cultures affects growth and multiplication in tissue culture experiments. However, various chemicals/ factors like antibiotics, fungicides, heat and light have been adapted to eliminate fungal and bacterial contaminants (Sen et al., 2013c; Ramakrishnan et al., 2014).

Frequency of contamination is reported to be high in $A$. aspera cultures, since there is presence of contaminating microorganisms within the explants (endophytic) or on the surface. Limited number of research studies have been undertaken to document the success of eradicating contaminants. Various sterilizing agents were used to surface sterilize the explants: seed, young shoot, stem/ shoot, leaf, node, internode and root. They are detailed in the forthcoming sections.

\section{Surface sterilization of seeds}

Explants collected from field grown plants often show variations in growth characteristics in cultures as a result of change in soil nutrients and environmental conditions. This problem can be overcome by collecting explants from in vitro germinated seedlings under standard physico-chemical conditions. Consequently, in vitro seed germination becomes prerequisite for the source of any kind of explant to establish synchronized cultures.

In vitro seed germination studies of $A$. aspera had been carried out by Sen et al. (Sen et al., 2013c). Dried, cleaned husked and dehusked seeds were utilized for their study. Control seeds were surface sterilized only with $100 \%$ ethanol for $1 \mathrm{~min}$. Other seeds were washed first with $75 \%$ ethanol for $45 \mathrm{~s}$ (4-5 times) followed by treatment with different concentrations of Mercuric chloride $\left(\mathrm{HgCl}_{2}\right)$, Flugal, Nystatin or Sodium hypochlorite $(\mathrm{NaClO})$ containing a few drops of Tween20 for different time intervals. Later, seeds were rinsed with sterile distilled water. Dehusked seeds showed total germination and about $17 \%$ reduction in contamination when treated with $1 \% \mathrm{NaClO}$ solution. However, same concentration was not effective for husked seeds. Next to it, flugal was shown to be effective. The $\mathrm{HgCl}_{2}$ in the concentration of $0.1 \%$ (5 min) was effective in the germination of $90 \%$ of the dehusked and $70 \%$ of the husked seeds after ten days; however, half of the seeds were contaminated. Either increase in the duration of treatment or concentration of surface sterilizers exerted negative effect.

\section{Surface sterilization of stem}

For callus induction young stem explant could be surface sterilized with Tween-20 and $\mathrm{NaClO}$ solutions, and later with $0.1 \%$ of $\mathrm{HgCl}_{2}(2-5 \mathrm{~min})$. Finally the explants rinsed with sterile distilled water after each treatment (Senthilmanickam et al., 2012).

\section{Surface sterilization of leaf}

Leaves have mesophyll tissue and vascular cambium and are the most suitable explants for callus induction and/or organogenesis. The first report on in vitro culture of $A$. aspera leaf explants came in 2008 (Kayani et al., 2008). In that study, soft green leaves were surfaced sterilized by thorough washing with distilled water and incubated in $\mathrm{HgCl}_{2}(0.1 \%)$ solution for 2-3 min. Traces of $\mathrm{HgCl}_{2}$ on explants were removed by rinsing 3-4 times with sterile distilled water, like other explants. Surface sterilized explants were used for callus induction.

Establishment of successful contamination free cultures were not always easy in this plant since it has ecto- and endophytic fungal and bacterial association. Eradication of fungal and bacterial contaminants was also possible when surface sterilized with $0.1 \%$ of fungicide, Zen (contains 50\% carbendazim) followed by rinses with sterile distilled water for $1 \mathrm{~min}$. Subsequently the leaf explants were treated with low concentration $(0.05 \%)$ of $\mathrm{HgCl}_{2}$ solution ( $5 \mathrm{~min}$ ) followed by 3 times rinses with sterile distilled water ( $3 \mathrm{~min}$ each). These steps worked well in achieving $100 \%$ callus formation in the 
experiment carried out by Ramakrishnan et al. (2014). In the article published by Rathipriya et al. (2015) claimed that they had multiplied $A$. aspera after surface sterilizing leaf explants first with 5\% Teepol and then with $0.1 \% \mathrm{HgCl}_{2}$ solution (10 min each), and several rinses with distilled water after every step.

\section{Surface sterilization of node}

Nodal explant was used in the study conducted by Sen et al. (2013b) at Plant Biotechnology Division of National Institute of Biotechnology, Dhaka, Bangladesh. They employed the sequential steps to surface sterilize the explants: (a) washing in running tap water followed by liquid detergent wash, (b) treatment with Bavistin, Flugal, Nistatin, Ridomil Gold or $\mathrm{HgCl}_{2}$ at different concentrations and durations, (c) rinsing with running tap water and (d) finally treatment with $70 \%$ ethanol for 45 sec. Flugal treatment (3\% for $10 \mathrm{~min}$ ) followed by $\mathrm{HgCl}_{2}$ ( $0.1 \%$ for $2-3 \mathrm{~min})$ favoured the formation of shoots with less contamination and $65 \%$ survival rate.

More survival rate of explants $(95 \%)$ was achieved by Gnanaraj and co-researchers (Gnanaraj et al., 2012). Young shoots with nodal explants treated with $\mathrm{HgCl}_{2}$ $(0.1 \%)$ for $1 \mathrm{~min}$ preceded by Bavistin $(0.1 \%)$ treatment. The explants were rinsed 2-4 times with sterile distilled water after each treatment. Though, further increase in $\mathrm{HgCl}_{2}$ was also effective in surface sterilization but reduced the survival rate of explants.

\section{Surface sterilization of leaf, internode and root}

Leaf, internode and root explants were successfully surface sterilized by Sen et al. (Sen et al., 2014), initially cleaned them using tap water and disinfecting them with $0.5 \%$ Bavistin (10-12 $\mathrm{min}$ ) followed by treatment with $10 \%$ Teepol/ Tween 20 (2 min). Later the explants were subjected to $70 \%$ ethanol $(45 \mathrm{~s})$ and $0.1 \% \mathrm{HgCl}_{2}(2-3$ min). Finally they were washed 3-4 times with sterile distilled water prior to inoculation. The above procedure resulted in highest culture survival rate of internodal explants (about 95\%) followed by leaf (over 75\%) and root (over $40 \%$ ). Similar surface sterilization treatment was adapted for young leaves and internodal explants in another study (Naz and Khatoon, 2014).

\section{Surface sterilization of node}

Surface sterilization of nodal explant of A. aspera was done with $0.1 \% \mathrm{HgCl}_{2}$ containing Tween-20 (few drops) for 10 min with intermittent shaking followed by several times rinses with sterile distilled water. These explants were utilized for callus induction on MS medium fortified with various auxins (Naz and Khatoon, 2014).

\section{Callogenesis}

Callus induction and multiple shoot formation have been done in A. aspera from various explants employing culture media augmented with different PGRs. Among various plant tissue culture media, MS medium (Murashige and Skoog, 1962) or its modifications has produced satisfactory results for several plant species (Rout and Das, 1997; Ramakrishnan et al., 2014). Production of callus from explants mainly depends upon determination of an adequate balance of growth regulators. Only a minimum number of callogenic studies have been reported in this plant.

\section{Callus from leaves}

First report on callus induction was published by Kayani et al. (2008) of Quaid-i-Azam University of Islamabad. Their study exposed the callusing potential of leaf explants on MS medium and different concentrations of auxins (2,4-D, IAA, IBA, NAA) and cytokinins (BAP, KIN, Zeatin). Cultures were maintained in growth room at 25 or $26^{\circ} \mathrm{C}$ and $16 \mathrm{~h}$ light cycle. Combination of 2,4-D (2 mg/l) and NAA $(0.5 \mathrm{mg} / \mathrm{l})$ gave better result in callus induction (Table $1)$. The callus produced was light green, soft, nonembryogenic and compact. Callus formation with the similar morphological features was also observed in the media containing 2,4-D+BAP, however, the callus colour was changed to light brown.

Table 1. Callusing potential of leaf explants of A. aspera on MS medium.

\begin{tabular}{lllll}
\hline $\begin{array}{l}\text { Plant growth } \\
\text { regulators (mg/l) }\end{array}$ & Callus & & & References \\
\cline { 2 - 4 } 2,4-D (1) & Colour & Texture & Callusing (\%) & Ramakrishnan et al. (2014) \\
2,4-D (2) & Cale brown & -- & 100 & Naz and Khatoon (2014) \\
2,4-D (2)+NAA (0.5) & Light green & Soft, compact & -- & Kayani et al. (2008) \\
& Luxuriant greenish & Friable & 100 & Sen et al. (2014) \\
2,4,5-T (7) & Whitish green & Soft & 100 & Ramakrishnan et al. (2014) \\
\hline
\end{tabular}

K. Nandhini and S. Ramakrishnan (2016) / A Review on In Vitro Culture Studies of a Traditional Medicinal HerbAchyranthes aspera L. 
An attempt has been made to evaluate the callusing potential of leaf explant collected from in vivo plant on MS and B5 media supplemented with PGRs such as 2,4D, 2,4,5-T, NAA, IBA, BAP, KIN in our previous study (Table 1) (Ramakrishnan et al., 2014). Cultures were incubated under light and dark conditions. The temperature was maintained at $25 \pm 2^{\circ} \mathrm{C}$. The MS medium augmented with $1 \mathrm{mg} / \mathrm{l} 2,4-\mathrm{D}$ or 7 (or 8 ) $\mathrm{mg} / \mathrm{l}$ 2,4,5- T resulted in high frequency of callus formation $(100 \%$ each) under light incubation. Subsequently the colour of the callus turned brown after 2 weeks. Further, leaf cultured on MS+ 2,4,5-T (8 mg/l) under dark condition promoted good callogenesis. Subculture of the callus on to MS basal medium retained green colour of the callus.
However, B5 medium (Gamborg et al., 1968) was not effective in callus induction under dark condition.

\section{Callus from stem}

Stem is not usually preferred as an explant for callus production. The young stem was used as explant for callus induction in a study (Table 2). In that 2,4-D and NAA in different concentrations were supplemented in MS medium. Callus induction was good in the culture media fortified either with 2,4-D (2 mg/l) or NAA (4 $\mathrm{mg} / \mathrm{l})$. Synergistic effect of these two PGRs in equal proportion (1 $\mathrm{mg} / \mathrm{l})$ evinced good callogenesis (Senthilmanickam et al., 2012).

Table 2. Callusing potential of stem, nodal and internodal explants of A. aspera on MS medium.

\begin{tabular}{|c|c|c|c|c|c|}
\hline \multirow{2}{*}{$\begin{array}{l}\text { Explant } \\
\text { type }\end{array}$} & \multirow{2}{*}{$\begin{array}{l}\text { Plant growth } \\
\text { regulators (mg/l) }\end{array}$} & \multicolumn{3}{|l|}{ Callus } & \multirow{2}{*}{ References } \\
\hline & & Colour & Texture & Callusing (\%) & \\
\hline Stem & 2,4-D (1) + NAA (1) & Yellowish green & -- & 100 & Senthilmanickam et al. (2012) \\
\hline Node & $2,4-\mathrm{D}(3.5)$ & Transparent & -- & 100 & Naz and Khatoon (2014) \\
\hline \multirow[t]{4}{*}{ Internode } & $2,4-\mathrm{D}(0.5)$ & -- & -- & 100 & Naz and Khatoon (2014) \\
\hline & 2,4-D (1) & Purple & -- & 80 & Sen et al. (2014) \\
\hline & $2,4-\mathrm{D}(2)+\mathrm{BAP}(0.5)$ & Copious purple & -- & 80 & Sen et al. (2014) \\
\hline & 2,4-D (2)+NAA (0.5) & Purple & Friable & 80 & Sen et al. (2014) \\
\hline
\end{tabular}

\section{Callus from internode, node, leaf and root}

Naz and Khatoon (2014) found out that internode, node and leaf explants responded differently on MS medium (having $3 \%$ sucrose and gelled with $0.6 \%$ agar) supplemented with various auxins and reported that leaf is a suitable explant for callus induction in 2,4-D (2 mg/l) medium. The orientation of the leaf was also equally important that adaxial side produced good extent of callus formation.

Similar study had been conducted using MS medium containing $3 \%$ sucrose and gelled with $0.8 \%$ agar by Sen et al. (Sen et al., 2014). The culture media were added with many concentrations of three auxins $(2,4-\mathrm{D}$, IAA,
NAA) and one cytokinin (BAP). At $2 \mathrm{mg} / \mathrm{l}$ the 2,4-D initiated good response in terms of callus induction in leaf and internodal explants. However, the callus formed from leaf explant was brownish in the above said concentration but not at $1 \mathrm{mg} / \mathrm{l}$ which induced green callus (Table 2).

A combination of $2,4-\mathrm{D}(2 \mathrm{mg} / \mathrm{l})$ with BAP $(0.5 \mathrm{mg} / \mathrm{l})$ proved better in friable callus induction from internodes (Table 2), roots (Table 3) and leaf. The colour of the leaf derived calli was brownish. However, from Table 1 it is suggested that the low concentration of NAA added with 2,4-D could prevent browning of leaf derived callus (Sen et al., 2014).

Table 3. Callusing potential of root explants of A. aspera on MS medium (Sen et al., 2014).

\begin{tabular}{llll}
\hline Plant growth regulators & \multicolumn{2}{l}{ Callus } & \\
\cline { 2 - 4 }$(\mathbf{m g} / \mathbf{l})$ & Colour & Texture & Callusing $(\%)$ \\
\hline 2,4-D (0.5) & Off white & Loose & 20 \\
2,4-D (2)+BAP $(0.5)$ & White & Friable & 30 \\
2,4-D (2)+NAA $(0.5)$ & White & Friable wet & 30 \\
2,4-D (1.5)+IAA (0.5) & Pale & Loose wet & 20 \\
\hline
\end{tabular}

\section{Multiple shoots formation}

Plant propagation without any alteration in the genetic makeup is crucial for success in plant breeding and other procedures like plant conservation and to main the species identity. Often indirect organogenesis (organogenesis via callus formation) results in genetic instability which will bring deleterious effects on 
plantlets produced in vitro (Phillips et al., 1994). Direct organogenesis or multiple shoots formation provides a way for the production of numerous plantlets from explants within a short span of time in tissue cultures with no genetic modification (Lakshmanan et al., 2007). Successful clonal propagation of $A$. aspera has been achieved in tissue culture studies.

\section{Direct shoot organogenesis}

The pioneering work on multiple shoot formation from nodal explant was carried out by Gnanaraj et al. (2012). Murashige and Skoog medium having 3\% sucrose, $0.6 \%$ agar and BAP, KIN, NAA, IAA was used for it. The BAP at $3 \mathrm{mg} / 1$ showed $>90 \%$ shoot initiation frequency. However, the number of multiple shoots produced was high in $5 \mathrm{mg} / \mathrm{l}$ BAP (ca. 10 shoots per explant) with $80 \%$ shoot initiation response. Good number of roots was induced from in vitro raised multiple shoots in half-strength medium fortified with $1 \mathrm{mg} / \mathrm{l}$ IBA. The IBA is a widely used PGR for rhizogenesis in cultures of many plant species (Levall and Bornman, 1993; Ramakrishnan and Kulandaivelu, 2007).

Direct multiple shoot formation from nodal explants (about 5 shoots per explant) has also been reported by Sen et al. (2013a) not with full strength but with half strength MS medium plus $3 \mathrm{mg} / \mathrm{l} \mathrm{BAP}$. The reduction in the number of shoots produced from nodal explants in this study perhaps due to low strength of the medium and increased agar content $(0.8 \%)$. Sucrose level used in this study was same like that of the experiment conducted by Gnanaraj et al. (2012). Agar at low concentration $(0.6 \%)$ may promote initiation of A. aspera shoots in large numbers which could be authenticated by further researches only.

\section{Indirect shoot organogenesis}

In some cultures the callus is formed first and shoots induced from it later. Leaf and internodal segments derived calli cultured on MS medium produced about 5 shoots by $4 \mathrm{mg} / \mathrm{l} \mathrm{BAP}+0.5 \mathrm{mg} / \mathrm{l} \mathrm{KIN} \mathrm{(Sen} \mathrm{et} \mathrm{al.,}$ 2014). However, indirect shoot formation from leaf and internode explants has been less suitable than direct organogenesis by nodal explant. An amateur research study on the multiplication of A. aspera explants were carried out by Rathipriya and coworkers (2015). They claimed that they had multiplied the plant in vitro using nodal and shoot tip explants on MS medium added with IAA and BAP. Unfortunately, there was no mentioning by them on the concentrations of the PGRs used and the concentration in which more number of multiple shoots formed.

The above kinds of situations also lead us to review the culture experiments on this plant so as to enable the researchers on the exact developments and lacunae of the research in this important medicinal plant.

\section{Study on secondary metabolites}

Many higher plants are major sources/ reservoirs of natural products which are used as pharmaceuticals, agrochemicals, flavour and fragrance ingredients, food additives and pesticides (Balandrin and Klocke, 1988). The accumulation of secondary metabolites in plant cell culture depends on the composition of the culture medium, elicitors, physical conditions and the type of explants (Vanisree et al., 2004). In vitro grown plant cells and tissues have been used extensively for the production of secondary metabolites (Senthilmanickam et al., 2012).

Even though, A. aspera whole plant is used as medicine, till date no quantitative estimation and fruitful analysis of secondary metabolites from tissue culture raised plant have been reported. The callus of this plant becomes brown colour when formed in MS medium+2,4-D, under in vitro culture conditions.

Many studies conducted to isolate and identify secondary metabolites from in vivo grown A. aspera. Some of the metabolites identified are water soluble betaine (Kapoor and Singh, 1966), chloroform soluble alkaloids (Kapoor and Singh, 1967), ethanol soluble alkaloids and saponins (Kumar et al., 1990), 36,47-dihydroxyhenpentacontan-4one, tritriacontanol (Misra et al., 1991), ecdysterone (Banerji et al., 1971), flavonoids (Sinha and Dogra, 1985), etc.

So far methods to produce or isolate these or other compounds from tissue culture grown A. aspera have not yet been formulated. An attempt has been made to study the presence of secondary metabolites from callus. Stem explant of $A$. aspera inoculated on MS medium having 2,4-D and NAA (1 mg/l each) induced yellowish green callus. Thin layer chromatographic separation of callus extract indicated the presence of steroids, alkaloids and sugars (Senthilmanickam et al., 2012). This is only a qualitative report but quantitative estimation and identification of secondary metabolites needed to be assessed by future studies. 


\section{Conclusion}

Dehusked seeds of Achyranthes aspera are most suitable for in vitro germination. For surface sterilization $\mathrm{HgCl}_{2}$ and Bavistin have proved better with less contamination rate. Leaf is a suitable explant for callus induction and 2,4-D favours it. So far only protocols for callus and multiple shoots formation have been documented for this valuable plant but not the pollen, anther, ovule cultures or somatic embryogenesis. Isolation of secondary metabolites from in vitro cultures has not become a routine procedure or popular till now in this medicinal plant. These areas could be focused in the future research studies to formulate therapeutic drugs.

\section{Conflict of interest statement}

Authors declare that they have no conflict of interest.

\section{References}

Balandrin, M.J., Klocke, J.A., 1988. Medicinal, aromatic and industrial materials from plants. In: Biotechnology in Agriculture and Forestry. Medicinal and Aromatic Plants Vol. 4 (Ed.: Bajaj, Y. P. S.) Springer-Verlag, Berlin. pp. 3-36.

Banerji, A., Chintalwar, G.J., Joshi, N.K., Chadha, M.S., 1971. Isolation of ecdysterone from Indian plants. Phytochemistry. 20, 2225-2226.

Bhattaraj, N.K., 1992. Folk use of plants in veterinary medicine in Central Nepal. Fitoterapia. LXVII(3), 497506.

Gamborg, O.L., Miller, R.A., Ojima, K., 1968. Nutrient requirements of suspension cultures of soybean root cells. Exp. Cell Res. 50, 151-158.

Ganesan, S., Venkatesan, G., Bhanumathi, N., 2006. Medicinal plants used by ethnic group Thottinaickkans of Semmali (Reserved forest), Thiruchirappalli district, Tamil nadu. Ind. J. Trad. Knowl. 5(2), 245-252.

Gnanaraj, W.E., Antonisamy, J.M., Mohanamathi, R.B., Subramanian, K., 2012. In vitro clonal propagation of Achyranthes aspera L. and Achyranthes bidentata Blume using nodal explants. Asian Pac. J. Trop. Biomed. 2(1), 15.

Kapoor, V.K., Singh, H., 1966. Isolation of betaine from Achyranthes aspera Linn. Ind. J. Chem. 4, 461.

Kapoor, V.K., Singh, H., 1967. Investigation of Achyranthes aspera Linn. Ind. J. Pharm. 29, 285-288.

Kayani, S., Zia, M., Sarwar, S., Rehman, R.U., Chaudhary, M.F., 2008. Callogenic studies of Achyranthes aspera leaf at different hormonal combinations. Pak. J. Biol. Sci. 11(6), 950-952.

Kumar, S., Singh, J.P., Kumar, S., 1990. Phytochemical screening of some plants of Manipur-I. J. Econ. Bot. Phytochem. 1, 13-16.
Lakshmanan, V., Venkataramareddy, S.R., Neelwarne, B., 2007. Molecular analysis of genetic stability in long-term micropropagated shoots of banana using RAPD and ISSR markers. Electr. J. Biotech. 10(1), 106-113.

Levall, M.W., Bornman, J.F., 1993. Selection in vitro for UVtolerant sugar beet (Beta vulgaris) somaclones. Physiol. Plant. 88, 37-43.

Misra, T.N., Singh, R.S., Pandey, H.S., Prasad, C., 1991. An aliphatic dihydroxyketone from Achyranthes aspera. Phytochemistry. 30, 2076-2078.

Murashige, T., Skoog, F., 1962. A revised medium for rapid growth and bioassays with tobacco tissue culture. Physiol. Plant. 15, 473-497.

Nadkarni, K.M., 2009. Indian Materia Medica. $1^{\text {st }}$ Edn. Bombay Popular Prakashan, India. 21p.

Naz, S., Khatoon, K., 2014. The effect of auxins on callus induction in Achyranthes aspera. Pak. J. Bot. 46(6), 22032207.

Pande, P.C., Tiwari, L., Pande, H.C., 2007. Ethnoveterinary plants of Uttaranchal- A review. Ind. J. Trad. Knowl. 6(3), 444-458.

Phillips, R.L., Kaeppler, S.M., Olhoft, P., 1994. Genetic instability of plant tissue cultures: Breakdown of normal controls. Proc. Nat. Acad. Sci. USA. 91, 5222-5226.

Ramakrishnan, S., Kulandaivelu, G., 2007. Induction of UV-B resistance in rice (Oryza sativa L. cv. ADT 43) through adaptive mutagenesis-I.: Optimization of tissue culture and UV-irradiation condition. J. Plant Biol. 34(3), 205-212.

Ramakrishnan, S., Nandhini, K., Porkalai, A., Allirani, S., Subathra, A., Ilakkia, R., Jayalakshmi, P., Kalaivani, P., 2014. Auxins and physico-chemical factors influenced callus formation in Achyranthes aspera L. leaf explant. J. Microb. Biotech. Food Sci. 3(6), 444-447.

Rathipriya, C.S., Rajalakshmi, G., Komathi, S., Surendran, L., 2015. Mass multiplication, phytochemical, antibacterial and molecular analysis of an important medicinal plant Achyranthes aspera Linn. Int. J. Res. Stud. Biosci. 3(3), 34-42.

Rout, G.R., Das, P., 1997. In vitro organogenesis in ginger (Zingiber officinale Rosc.). J. Herbs Spices Med. Plants. 4(4), 41-51.

Sen, M.K., Nasrin, S., Rahman, S., Jamal, A.H.M., 2014. In vitro callus induction and plantlet regeneration of Achyranthes aspera L., a high value medicinal plant. Asian Pac. J .Trop. Biomed. 4(1), 40-46.

Sen, M.K., Jamal, M.A.H.M., Nasrin, S., 2013a. Sterilization factors affect seed germination and proliferation of Achyranthes aspera cultured in vitro. Environ. Exp. Biol. 11, 119-123.

Sen, M.K., Hassan, Md.M., Nasrin, S., Jamal, M.A.H.M., Mamun-Or-Rashid, A.N.M., Dash, B.K., 2013b. In vitro sterilization protocol for micropropagation of Achyranthes aspera L. node. Int. Res. J. Biotech. 4(5), 89-93.

Sen, M.K., Hassan, Md.M., Nasrin, S., Jamal, M.A.H.M., Mamun-Or-Rashid, A.N.M., Biswas, N., 2013c. An efficient plant regeneration protocol for Achyranthes aspera L. Int Res J Biotech. 4(5), 94-100. 
Senthilmanickam, J., Lakshmi Bhavani, A., Venkatramlingam, K., Chandra, G., 2012. The role of 2, 4-D and NAA in callus induction of Achyranthes aspera and its secondary metabolite studies. Jamonline. 2(3), 232-243.

Sinha, S.K.P., Dogra, J.V.V., 1985. A survey of the plants of Bhagalpur and Santhal Pargana for saponin, flavonoids and alkaloids. Int. J. Crude Drug Res. 23, 77-86.

Srivastav, S., Singh, P., Mishra, G., Jha, K.K., Khosa, R.L., 2011. Achyranthes aspera- an important medicinal plant: A review. J. Nat. Prod. Plant Resour. 1(1), 1-14.
Vanisree, M., Lee, C.Y., Lo, S.F., Nalawade, S.M., Lin, C.Y., Tsay, H.S., 2004. Studies on the production of some important secondary metabolites from medicinal plants by plant tissue cultures. Bot. Bull. Acad. Sin. 45, 1-22.

Verma, R.K., 2014. Ethnomedicinal potential of Achyranthes aspera Linn. (Amaranthaceae). Int. J. Sci. Res. 3(6), 5560.

WHO, 1993. Research guidelines for evaluating the safety and efficacy of herbal medicines. Regional Office for Western Pacific. Manila.

\section{How to cite this article:}

Nandhini, K., Ramakrishnan, S., 2016. A review on in vitro culture studies of a traditional medicinal herbAchyranthes aspera L.. Int. J. Curr. Res. Biosci. Plant Biol. 3(9), 57-63.

doi: http://dx.doi.org/10.20546/ijcrbp.2016.309.008 